\title{
Separation and determination of colloidal trace metals in seawater by cross- flow ultrafiltration, liquid-liquid extraction and ICP-MS
}

\author{
Yuxi $\mathrm{Lu}^{\mathrm{a}, \mathrm{b}}$, Xuelu Gao ${ }^{\mathrm{a}, \mathrm{b}, *}$, Chen-Tung Arthur Chen ${ }^{\mathrm{c}}$ \\ ${ }^{\text {a }}$ CAS Key Laboratory of Coastal Environmental Processes and Ecological Remediation, Yantai Institute of Coastal Zone Research, Chinese Academy of Sciences, Yantai, \\ Shandong 264003, China \\ ${ }^{\mathrm{b}}$ University of Chinese Academy of Sciences, Beijing 100049, China \\ ${ }^{\mathrm{c}}$ Department of Oceanography, National Sun Yat-sen University, Kaohsiung 80424, Taiwan
}

A R T I C L E I N F O

\section{Keywords:}

Colloidal trace metals

Seawater

Pre-concentration

Inductively coupled plasma mass spectrometry

\begin{abstract}
A B S T R A C T
In this study, a method was developed for the desalination and pre-concentration of three colloidal trace metals in seawater, namely $\mathrm{Cd}, \mathrm{Cu}$ and $\mathrm{Pb}$, using diethylammonium diethyldithiocarbamate and ammonium 1-pyrrolidine dithiocarbamate as chelates. Seawater samples were first treated with cross-flow ultrafiltration (CFUF) for the separation of the colloidal matter of different molecular weights, i.e. $1-3 \mathrm{kDa}, 3-10 \mathrm{kDa}$ and $10 \mathrm{kDa}-0.22 \mu \mathrm{m}$. Then, after acid digestion, the organic chelates and the extracting agent chloroform were added at $\mathrm{pH}=3.8$. Finally, the organic phase was back extracted, and the target metals in all samples were measured using inductively coupled plasma mass spectrometry (ICP-MS) with low detection limits in the range of $0.13-1.18 \mathrm{pmol} \mathrm{L}^{-1}$. The extraction efficiencies for the three metals were in the range of $92.2 \%-100.3 \%$ with an enrichment factor of 40, and their mass recoveries in the studied colloidal fractions were in the range of 83.1\%-103.5\%. The developed method has been successfully applied for the analysis of seawater samples collected from the sites off the south coast of North Yellow Sea in Shandong Peninsula, China. For the first time, the distribution of colloidal $\mathrm{Cd}, \mathrm{Cu}$ and $\mathrm{Pb}$ in different molecular weights in this area is reported. The results obtained from real samples demonstrate that the developed method is simple, efficient and convenient for routine analysis with low detection limit.
\end{abstract}

\section{Introduction}

Aquatic colloids are known to be abundant and conventionally defined as nanoparticles and macromolecules with the size ranging from $1 \mathrm{~nm}$ to $1 \mu \mathrm{m}$ (Gustafsson and Gschwend, 1997; Guo and Santschi, 2007; Santschi, 2018). In environmental studies, $0.45 \mu \mathrm{m}$ filters are typically used to separate the water into particles and dissolved phases, ignoring the presence of colloids (Waeles et al., 2008; Gu et al., 2013), which led to limited research in this field. The colloids in water bodies are unstable and susceptible to changes in microtopography, polymerization, and sedimentation. In addition, due to their high molecular weight and large specific surface area, the reactive functional groups attached to the surface of colloids can strongly adsorb and complex with nutrients, trace metals and various organic contaminants in aquatic environments (Buffle, 2006; Hochella et al., 2008; Auffan et al., 2009). As is known, the ions of some metals such as $\mathrm{Cd}, \mathrm{Cu}$ and $\mathrm{Pb}$ are toxic and could have serious harmful effects on life over certain concentrations (Manju et al., 2015). The functional groups of colloids, such as carboxyl groups, hydroxyl groups and amino groups, have strong adsorption and complexing ability with metal ions in water body, which can significantly affect their solubility, migration, sedimentation, bioavailability and toxicity. Meanwhile, studies have found that high molecular weight organic matter in colloids is easily absorbed by microorganisms (Amon and Benner, 1996). Coastal seas are a vast sink of anthropogenic contaminants, and they are also the place where people farm to get seafood (Huang et al., 2013). Trace metals in coastal seas, especially those with high toxic effects on living organisms, can be enriched through the food chain and eventually reach higher concentrations, threatening human health. However, due to a lack of efficient and clean pretreatment methods, high quality data on the publication of colloidal metals in the coastal waters of China are scarce. Therefore, it is of great significance to develop an efficient separation and determination method to study the biogeochemistry of trace metals in various phases of water bodies (Um and Papelis, 2002; Huang et al.,

\footnotetext{
* Corresponding author at: CAS Key Laboratory of Coastal Environmental Processes and Ecological Remediation, Yantai Institute of Coastal Zone Research, Chinese Academy of Sciences, Yantai, Shandong 264003, China.

E-mail address: xlgao@yic.ac.cn (X. Gao).
} 
2015; Markus et al., 2018).

Cross-flow ultrafiltration (CFUF), a commonly used colloidal separation technique, can separate colloids from aquatic systems based on their molecular weight or size in environmental research (Powell et al., 1996; Liu et al., 2013). The application of CFUF in the study of aquatic systems, especially that of the distribution of metals between the colloidal phase, e.g. the dissolved matter of $>1 \mathrm{kDa}$, and the truly dissolved phase, e.g. the dissolved matter of $<1 \mathrm{kDa}$, provides valuable information on the biogeochemistry of trace elements in aquatic systems (Guo et al., 2007; Gu et al., 2013). In comparison with other separation techniques, CFUF can process quickly large volumes of water samples, which can ensure more subsequent research (Pokrovsky et al., 2012; Huang et al., 2014). However, after seawater sample was ultrafiltered, the retentate and ultrafiltrate contain high concentrations of sodium chloride, which will interfere with the signal value of the target element in the subsequent analysis (Biparva and Matin, 2012; Liu et al., 2018). Meanwhile, for some metals with lower concentration, such as $\mathrm{Cd}$ and $\mathrm{Pb}$, contamination may occur during the collection and routine instrument analysis, which may result in the final measured concentration being higher than the true value (Li et al., 2015). Thus, it is necessary to select an appropriate pretreatment method, e.g. liquid-liquid extraction, to enrich the colloidal trace metals separated after CFUF processing. By this approach, the concentration of trace metals can be concentrated, and in addtion, the effect of high concentration of sodium chloride on the detection results can be eliminated and the accuracy of the results can be guaranteed.

In this study, for the first time, we combined a liquid-liquid extraction method with CFUF and ICP-MS, and successfully detected colloidal trace metals of different molecular weights, i.e. $1-3 \mathrm{kDa}$, $3-10 \mathrm{kDa}$ and $10 \mathrm{kDa}-0.22 \mu \mathrm{m}$, in the coastal waters of Shandong Peninsula, North Yellow Sea (NYS), China. Diethylammonium diethyldithiocarbamate (DDDC) and ammonium 1-pyrrolidine dithiocarbamate (APDC) were used as the chelates in the applied liquid-liquid extraction by referencing Li et al. (2015). The application of clean colloidal trace metal separation and determination techniques ensures good accuracy, low detection limits and high recovery of spiked samples. In addition, the data demonstrate the feasibility of the developed method and the reliability of the data. The distributions of the target metals in the colloidal fractions with different molecular weight ranges in the study area are discussed.

\section{Experiment and methods}

\subsection{Reagents}

The mixed standard solutions for the three target elements $(\mathrm{Cd}, \mathrm{Cu}$ and $\mathrm{Pb}, 1000 \mathrm{mg} \mathrm{L}^{-1}$ ) were purchased from General Research Institute for Nonferrous Metals (China). APDC (Guaranteed reagent) was purchased from Aladdin Industrial Corporation (Shanghai, China), and DDDC (Guaranteed reagent) was supplied by TCI Chemical Industry Co., Ltd. (Shanghai, China). The concentrated nitric acid $\left(\mathrm{HNO}_{3}\right)$ and concentrated hydrochloric acid $(\mathrm{HCl})$ were obtained by re-distilling trace metal grade $\mathrm{HNO}_{3}$ (Sinopharm Chemical Reagent Co., Ltd., China) and $\mathrm{HCl}$ (Sinopharm Chemical Reagent Co., Ltd., China) with a subboiling distillation apparatus (BSB-939-IR, Berghof, Germany). The polypropylene sampling bottles (Thermo ${ }^{\circ}$ ) were pre-cleaned following a cleaning process modified from Li et al. (2015), i.e. first cleaned with 10\% Decon $90^{\mathrm{TM}}$ (Decon Laboratories Ltd., UK), and then sonicated successively in $1.5 \mathrm{~mol} \mathrm{~L}^{-1} \mathrm{HNO}_{3}, 1.2 \mathrm{~mol} \mathrm{~L}^{-1} \mathrm{HCl}$, and ultra-pure deionized water (DIW; $18.2 \mathrm{M} \Omega-\mathrm{cm}$ ) for $3 \mathrm{~h}$. The DIW used in this work was made by a Pall Cascada ${ }^{\mathrm{TM}}$ lab water purification system (Pall Corporation). Each sampling bottle was double bagged in polyethylene bags, and stored at $20-25^{\circ} \mathrm{C}$ for further use. All the experimental labware used in this study was also pre-cleaned following the above cleaning process and dried in a Class 100 clean bench. The experimental operations were also carried out in the clean bench at $\sim 25^{\circ} \mathrm{C}$.

\subsection{Sampling}

Field samples used in this study were surface seawater (1-2 $\mathrm{m}$ deep) collected from 2 sites off the north coast of Shandong Peninsula, the NYS, in May and September 2018, respectively (Supplementary Material Fig. S1). Site Y1 was located in the Sishili Bay, a busy region in the south coast of the NYS, which is greatly affected by aquaculture and human activities (Zhang et al., 2016); site Y2 was located in the Rongcheng Bay, a fast-growing aquaculture area, which was an important part of the Shandong Peninsula Blue Economic Zone in the national development strategy of China (Yang et al., 2001; Huang et al., 2013). Samples were collected in pre-cleaned polypropylene bottles that had been flushed in the field with seawater. Then in the laboratory, the samples were filtered through Supor $-2000.22 \mu \mathrm{m}$ membrane filters (Pall Corporation) and collected in pre-cleaned $4 \mathrm{~L}$ polypropylene bottles and then stored at $4{ }^{\circ} \mathrm{C}$ before further processing. In order to ensure the accuracy of the experimental results, the sampled seawater was filtered within $4 \mathrm{~h}$ (Waeles et al., 2008; Xu et al., 2018).

\subsection{Cross-flow ultrafiltration}

Millipore Prep/scale ${ }^{\mathrm{TM}}$ devices with regenerated cellulose membranes of 1,3 and $10 \mathrm{kDa}$ nominal pore size, respectively, were set up for the size fractionation of water samples. The schematic diagram of the CFUF system is shown in Supplementary Material Fig. S2. Before each experiment, the CFUF system was pre-cleaned using the method reported in Guo and Santschi (1997). Briefly, the entire CFUF system, including membrane and C-flex ${ }^{\oplus}$ tubing (Cole-Parmer Inc.), was first cleaned with $2 \mathrm{~L}$ of $1 \%$ Micro-90 detergent and then recirculated with $0.2 \mathrm{~mol} \mathrm{~L}^{-1} \mathrm{NaOH}, 0.2 \mathrm{~mol} \mathrm{~L}^{-1} \mathrm{HCl}$ and DIW for $50 \mathrm{~min}$, respectively, to remove possible contamination. Finally, the system was rinsed with $1 \mathrm{~L}$ of seawater sample before CFUF. In short, $10 \mathrm{~L}$ of seawater prefiltered with $0.22 \mu \mathrm{m}$ filters were sequentially passed through three CFUF systems with 10, 3 and $1 \mathrm{kDa}$ molecular weight cutoffs, respectively, using a peristaltic pump (Masterflex ${ }^{\varpi} \mathrm{L} / \mathrm{S}$, Cole-Parmer Inc.), and the permeate flow with the matter less than the molecular weight cutoff of the CFUF membrane was directed into a permeation reservoir (Reservoir 2, Supplementary Material Fig. S2) until the concentration factor ( $c f$ ) reached around 15-20. The flow rate during rinsing and CFUF was $30-40 \mathrm{~mL} \mathrm{~min}^{-1}$. After the CFUF treatment, the colloidal matter with $>1 \mathrm{kDa}$ molecular weight was significantly concentrated in the retentate reservoir (Reservoir 1, Supplementary Material Fig. S2).

As an important parameter affecting the CFUF efficiency, $c f$ can be used to describe the dynamic relationship between retentate volume and prefiltrate volume at any given time of ultrafiltration (Logan and Jiang, 1990). In previous studies, different $c f$ was applied to the study of colloidal matter. For example, Wen et al. (1996) used a macromolecular permeation model based on Kilduff and Weber (1992) to study colloidal metals in the Galveston Bay with a $c f$ of about 10. Liu et al. (2013) used a larger $c f$ of $\sim 17$ in the study of colloidal matter in some selected UK freshwaters. While in the study reported by Liu and Lead (2006), the reliable determination of colloidal components required a $c f$ of 15-20 in a research on the Vale Lake and Tern River, UK. Therefore, this range was used as the $c f$ throughout the present study.

\subsection{Liquid-liquid extraction}

To reduce the saline interference and enrich the target metals at the same time, we used a liquid-liquid extraction method reported in Li et al. (2015) to treat all tested samples, including the samples after CFUF separation, and the experiments were carried out in triplicate for every experimental condition.

Briefly, $400 \mathrm{~mL}$ of acidified seawater or colloidal samples were transferred into a Teflon separation funnel, then $5 \mathrm{~mL}$ of $\mathrm{pH} 3.8$ acetic acid-ammonium acetate buffer and $1.5 \mathrm{~mL}$ of superior grade ethanol solution containing $0.05 \mathrm{~mol} \mathrm{~L}^{-1}$ APDC and $0.04 \mathrm{~mol} \mathrm{~L}^{-1}$ DDDC were 

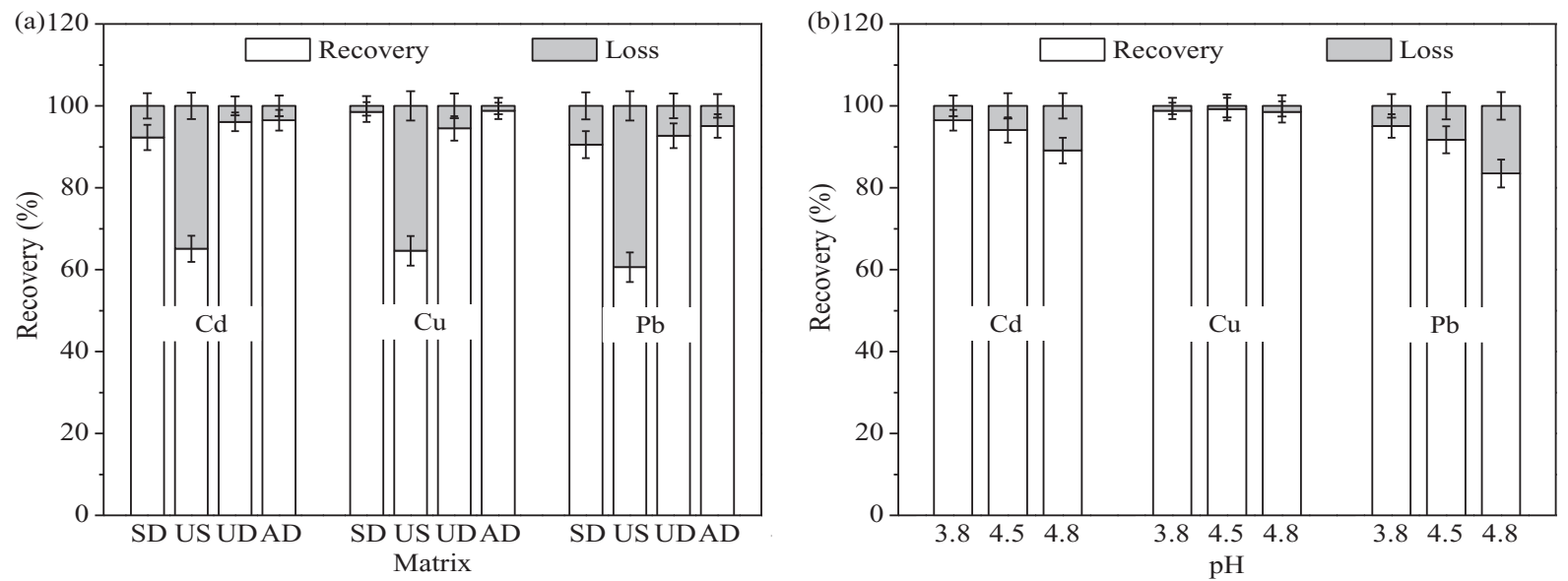

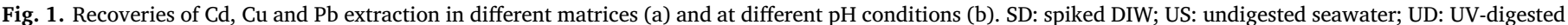
seawater; $\mathrm{AD}$ : acid-digested seawater.

added. The solution was then extracted with $5 \mathrm{~mL}$ chloroform 3 times and shaken for $1 \mathrm{~min}$ each time. Then, after separated from the extraction apparatus, the obtained chloroform phases were finally combined and $500 \mu \mathrm{L}$ of concentrated $\mathrm{HCl}$ and $500 \mu \mathrm{L}$ of concentrated $\mathrm{HNO}_{3}$ were pipetted to the chloroform phase to back-extract the target metals. The acid phase was pipetted into a pre-cleaned $15 \mathrm{~mL}$ centrifuge tube, then placed in a clean bench and left uncovered for $2 \mathrm{~h}$ for the evaporation of the remaining chloroform. Finally, $0.5 \mathrm{~mL}$ of the acid phase was then pipetted into another pre-cleaned $15 \mathrm{~mL}$ centrifuge tube and diluted to $5.0 \mathrm{~mL}$ with $0.5 \mathrm{~mol} \mathrm{~L}^{-1} \mathrm{HNO}_{3}$. The application of this method eliminated the possible interference of salt matrix and chloroform during instrumental analysis and concentrated the metals in each of the 3 colloidal fractions with the molecular weight ranges of $1-3 \mathrm{kDa}$, $3-10 \mathrm{kDa}$ and $10 \mathrm{kDa}-0.2 \mu \mathrm{m}$ obtained by CFUF for 40 times.

\subsection{Trace metal analysis and data processing}

In general, when the retentate, permeate, total dissolved concentration and $c f$ are known, colloidal metal concentrations can be calculated by difference (Buesseler et al., 1996). Therefore, after the necessary pretreatment, the pre-filtered seawater $(<0.22 \mu \mathrm{m})$, ultrafiltrate and retentate samples were measured using an inductively coupled plasma mass spectrometer (ICP-MS, ELAN DRC II, PerkinElmer ${ }^{\circ}$ ), and the concentration of each colloidal trace metal (1-3 kDa, $3-10 \mathrm{kDa}$ and $10 \mathrm{kDa}-0.22 \mu \mathrm{m})$ was calculated according to the following formula reported in Fu et al. (2011):

$C_{C 1 K}=\left(C_{R 1 K}-C_{T D}\right) c f 1$

$C_{C 3 K}=\left(C_{R 3 K}-C_{C 1 K}-C_{T D}\right) c f 2$

$C_{C 10 K}=\left(C_{R 10 K}-C_{C 3 K}-C_{C 1 K}-C_{T D}\right) c f 3$

in which, $C_{T D}$ is the concentration of truly dissolved phase $(<1 \mathrm{kDa})$; $c f 1, c f 2$ and $c f 3$ are the concentration factors (i.e. the volume of prefiltrate divided by the volume of retentate), which are stabilized at about 17 in this study; $C_{C 1 K}, C_{C 3 K}$ and $C_{C 10 K}$ are the concentration of colloidal metals of $1-3 \mathrm{kDa}, 3-10 \mathrm{kDa}$ and $10 \mathrm{kDa}-0.22 \mu \mathrm{m}$, respectively; $C_{R 1 K}, C_{R 3 K}$ and $C_{R 10 K}$ are the metal concentrations in the $1-3 \mathrm{kDa}, 3-10 \mathrm{kDa}$ and $10 \mathrm{kDa}-0.22 \mu \mathrm{m}$ retentates, respectively.

After the determination of every 12 samples, a mixed standard solution of target trace metals $\left(8.9 \mathrm{nmol} \mathrm{L}^{-1} \mathrm{Cd}, 15.7 \mathrm{nmol} \mathrm{L}^{-1} \mathrm{Cu}\right.$ and $4.8 \mathrm{nmol} \mathrm{L}^{-1} \mathrm{~Pb}$ ) in $1 \mathrm{~mol} \mathrm{~L}^{-1} \mathrm{HNO}_{3}$ was run on the ICP-MS as the quality control (Liu et al., 2018). The instrumental baseline was corrected by running the $1 \mathrm{~mol} \mathrm{~L}^{-1} \mathrm{HNO}_{3}$ to determine the instrument blank after every 12 injections.

\section{Results and discussion}

\subsection{Effects of the sample digestion method}

Complex matrices in seawater significantly affect the bonding between various metals and organic and inorganic ligands (Colombo et al., 2008). Previous studies have found that the dissolved organic matter (DOM) in aquatic system could significantly affect the behavior of metals (Turner et al., 2008; Cobelo-García, 2013). Therefore, the binding of DOM to metal in the sample must be removed before subsequent processing to minimize its impact on the experimental results.

In this research, the samples were pretreated with ultraviolet irradiation (Achterberg et al., 2001) and acid digestion (Li et al., 2015), which are two main methods for removing DOM from seawater, to determine the effects of the two pretreatment methods on the liquidliquid extraction rate. Briefly, in the UV irradiation process, seawater samples were irradiated under a $500 \mathrm{~W}$ high pressure mercury lamp (emission wavelength: $356 \mathrm{~nm}$, Model: GGZ500, Shanghai Jiguang Special Lighting Appliance Factory, China) for over $48 \mathrm{~h}$ until the concentration of background DOC was $<0.01 \mathrm{mg} \mathrm{L}^{-1}$ measured by a Shimadu TOC- $\mathrm{V}_{\mathrm{CPH}}$ carbon analyzer (Japan), which was consistent with corresponding result in Liu et al. (2018). The UV irradiation chamber was a $1 \mathrm{~L}$ quartz tank covered with a quartz cover embedded in a lid. The distance between the mercury lamp (in the middle of the chamber) and the sample was about $2 \mathrm{~cm}$. Concentrated $\mathrm{HNO}_{3}$ was added to the seawater sample to make its $\mathrm{pH}$ stable at 1.8 in the acid digestion process. In addition, for comparison, extraction experiments of $\mathrm{Cd}, \mathrm{Cu}$ and $\mathrm{Pb}$ in undigested natural seawater and spiked DIW were also carried out simultaneously. The spiked $\mathrm{Cd}, \mathrm{Cu}$ and $\mathrm{Pb}$ levels of the four pretreatment methods were $8.9,15.7$ and $4.8 \mathrm{nmol} \mathrm{L}^{-1}$, respectively.

As shown in Fig. 1a, various recovery efficiencies could be found for different matrices and metals, and high extraction efficiencies were obtained in both acid-digested and UV-digested samples. In contrast, however, the acid-digestion method had the advantage of the extraction efficiencies for $\mathrm{Cu}$ and $\mathrm{Pb}$. The extraction rate of the undigested sample was $<65.1 \%$ for all the three metals, indicating that organic matter in seawater could significantly reduce the extraction efficiency. In addition, similar recoveries of $\mathrm{Cd}, \mathrm{Cu}$ and $\mathrm{Pb}$ were obtained in the aciddigested sample and the spiked ultrapure water sample (Fig. 1a). Although UV digestion also has a good performance in terms of extraction efficiencies, considering the operation time, the acid digestion method was selected for the digestion of the samples.

\section{2. $p H$ conditions}

As an important factor, $\mathrm{pH}$ could significantly affect the binding 

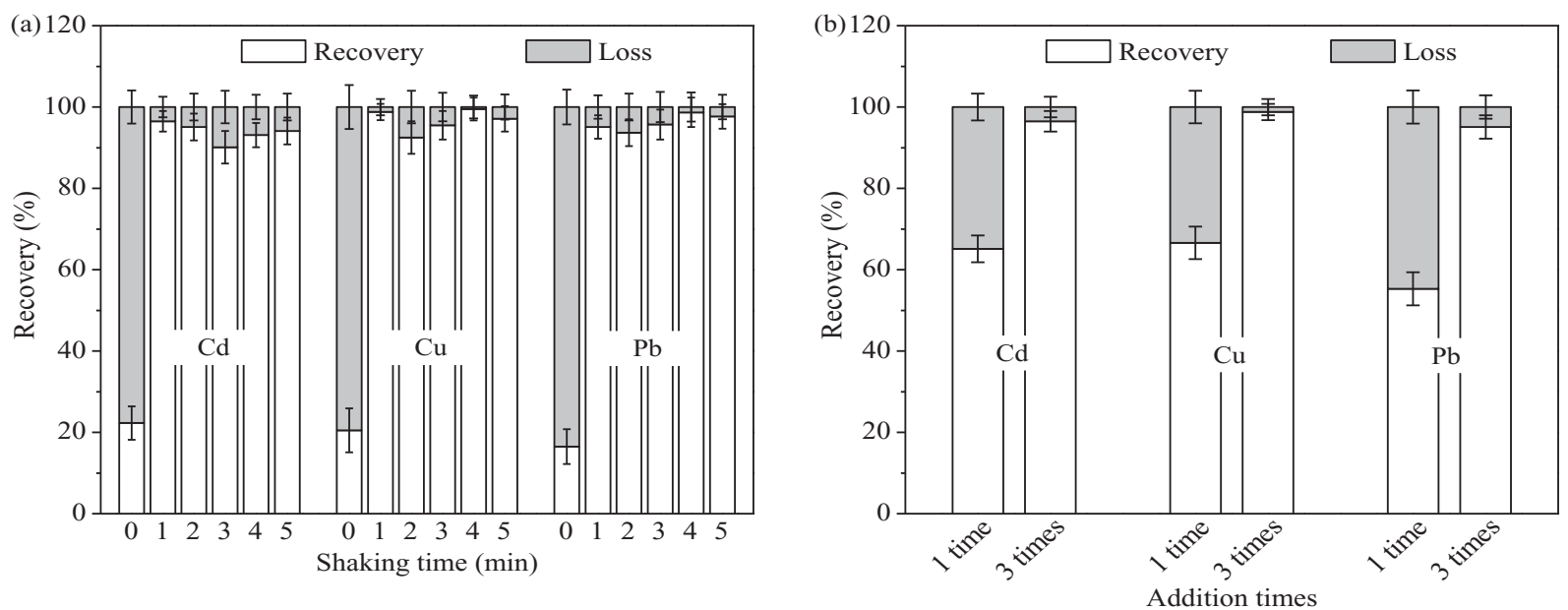

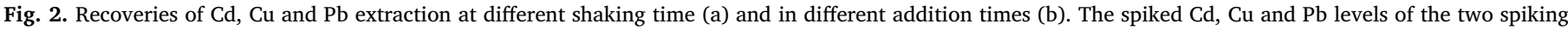
experiments were $8.9,15.7$ and $4.8 \mathrm{nmol} \mathrm{L}^{-1}$, respectively.

efficiency of organic chelates to trace elements (Pinto et al., 2015). Some studies have demonstrated that APDC and DDDC have excellent binding capabilities for many elements over a wide $\mathrm{pH}$ range of 2.5-5.5 (Bruland et al., 1979; Su et al., 2006; Wang and Wang, 2014). Therefore, we chose the acetic acid-ammonium acetate as the buffer in the extraction process, and three $\mathrm{pH}$ values, namely $3.8,4.5$ and 4.8 , were tested for the selection of the appropriate $\mathrm{pH}$. The standard solution with $8.9 \mathrm{nmol} \mathrm{L}^{-1} \mathrm{Cd}, 15.7 \mathrm{nmol} \mathrm{L}^{-1} \mathrm{Cu}$ and $4.8 \mathrm{nmol} \mathrm{L}^{-1} \mathrm{~Pb}$ was added to the acid digested seawater samples collected from site Y1 before they were subjected to the 3 parallel liquid-liquid extractions. The background values of three metals in the unspiked seawater were detected before calculating the final recovery.

As shown in Fig. 1b, it could be seen that these elements have different binding abilities to organic matter within this $\mathrm{pH}$ range. The recovery of $\mathrm{Cd}$ decreased significantly from $96.5 \%$ at $\mathrm{pH}=3.8$ to $89.1 \%$ at $\mathrm{pH}=4.8$. Similar to that of $\mathrm{Cd}$, the recovery of $\mathrm{Pb}$ decreased from $95.1 \%$ to $83.5 \%$ with the increase in $\mathrm{pH}$ from 3.8 to 4.8 . The recovery of $\mathrm{Cu}$ was relatively stable and $>98 \%$ at each tested $\mathrm{pH}$ value. Thus, we chose 3.8 as the optimum $\mathrm{pH}$ condition for the extraction process.

\subsection{Effects of the sample volume}

Due to the generally low concentration of $\mathrm{Cd}, \mathrm{Cu}$ and $\mathrm{Pb}$ in natural seawater (Srichandan et al., 2016; AlSuhaimi et al., 2017), improving the extraction efficiency can be achieved by increasing the enrichment factor. However, if the sample volume was too large during the experiment, the extraction time would be prolonged with the increasing amounts of the reagent, and a better extraction effect could not be necessarily obtained. On the contrary, if the sample volume was too small, it would be difficult to obtain the expected degree of enrichment and the accuracy of the experimental results would be affected. Therefore, 200 and $400 \mathrm{~mL}$ were selected as the experimental sample volumes to search the optimal sample volume for liquid-liquid extraction. In short, after the seawater was ultrafiltered through the $10 \mathrm{kDa}$, $3 \mathrm{kDa}$ and $1 \mathrm{kDa}$ CFUF devices, 200 and $400 \mathrm{~mL}$ of each of the $<1 \mathrm{kDa}$, $1-3 \mathrm{kDa}, 3-10 \mathrm{kDa}$ and $10 \mathrm{kDa}-0.22 \mu \mathrm{m}$ fractions were taken for enrichment, respectively. All fractions were treated repeatedly for 3 times, and then they were determined using ICP-MS to get the extraction efficiencies. Finally, the extraction efficiencies of the three metals for each of the sample volumes were compared. The results showed that the extraction efficiencies of the three elements for the $200 \mathrm{~mL}$ sample volume were $97.0 \%$ for $\mathrm{Cd}, 97.4 \%$ for $\mathrm{Cu}$ and $96.0 \%$ for $\mathrm{Pb}$, and the corresponding values for the $400 \mathrm{~mL}$ sample volume were $95.3 \%$ for $\mathrm{Cd}$, $98.8 \%$ for $\mathrm{Cu}$ and $95.1 \%$ for $\mathrm{Pb}$, which means there was no significant difference. However, when the sample volume was $400 \mathrm{~mL}$, the enrichment factor could reach 40 and was higher than that of the $200 \mathrm{~mL}$ sample volume, which has certain advantages in the operation. Moreover, the concentrations of the target metals in each of the subsamples were lower than their originals after separation by the CFUF system. Therefore, $400 \mathrm{~mL}$ was selected as the actual sample volume in the liquid-liquid extraction processing.

\subsection{Effects of the shaking time in extraction}

In the extraction process, when the time spent on shaking is insufficient, the target elements could not be effectively extracted. Conversely, it is inefficient and unnecessary to shake for a longer time when ideal extraction efficiency is achieved. Hence, six periods of shaking time spanned from 0 to $5 \mathrm{~min}$ with an increment of $1 \mathrm{~min}$ were tested for the selection of the proper one while the other experimental conditions were kept unchanged. Start shaking when chloroform was added to the solutions. 0 min means that no shaking operation was made, and chloroform settled to the bottom of the solutions under gravity. 3 parallel experiments were treated for each shaking time, and then they were determined using ICP-MS.

As shown in Fig. 2a, the extraction efficiencies of the three elements were $22.3 \%$ for $\mathrm{Cd}, 20.5 \%$ for $\mathrm{Cu}$ and $16.5 \%$ for $\mathrm{Pb}$ when no shaking operation was made. When the shaking time was $1-5 \mathrm{~min}$, the extraction rate was basically stable at above $90 \%$, which indicated that $1 \mathrm{~min}$ is enough and the extension of shaking time has little benefit for getting a higher extraction rate (Fig. 2a). This may be due to the fact that, after entering the aqueous phase, the organic phase disperses evenly and rapidly due to the action of the oscillation, and the system quickly reaches the extraction equilibrium (Sorouraddin et al., 2017). In order to minimize the extraction time and ensure a high extraction rate, we chose $1 \mathrm{~min}$ as the shaking time in extraction.

\subsection{Effects of the extractant volume and extraction method}

Besides by the methods of increasing the enrichment factor, a higher extraction rate could also be achieved by the selection of an appropriate extractant volume or adding method (Costa et al., 2018). In previous studies, 14-15 mL chloroform was added as the extractant (Bruland et al., 1979; Li et al., 2015). Bruland et al. (1979) used $14 \mathrm{~mL}$ chloroform, which was added in two portions with 6 and $8 \mathrm{~mL}$, to extract trace metals in $250 \mathrm{~g}$ seawater samples, and good recoveries were gained. Li et al. (2015) used $15 \mathrm{~mL}$ chloroform, which was added three times with $5 \mathrm{~mL}$ each time, to extract trace metals in $200 \mathrm{~g}$ seawater samples. Considering the larger sample volume $(400 \mathrm{~mL})$ in this study compared 
to the 200-250 $\mathrm{g}$ in Bruland et al. (1979) and Li et al. (2015), $15 \mathrm{~mL}$ of chloroform were added all at once and in three portions with $5 \mathrm{~mL}$ each time to compare the extraction efficiencies of the three metals. After adding chloroform, the system was shaken for $1 \mathrm{~min}$. For the three-time addition experiments, the extractants were collected and mixed together, and then subjected to further processing.

As shown in Fig. 2b, although the one-time addition method could simplify the experimental operation process and shorten the pretreatment time, the recoveries of $\mathrm{Cd}, \mathrm{Cu}$ and $\mathrm{Pb}$ it got were all lower than $70 \%$, especially for $\mathrm{Pb}$, which was only $55.3 \%$. For the three-time addition method, the recoveries of $\mathrm{Cd}, \mathrm{Cu}$ and $\mathrm{Pb}$ were $96.5 \%, 98.8 \%$ and $95.1 \%$, respectively. Although the extraction time was prolonged, ideal extraction rates could be guaranteed using the three-time addition method. Therefore, adding $5 \mathrm{~mL}$ chloroform each time for 3 times was applied in this research.

\subsection{Method validation}

\subsubsection{Detection limit (LOD) and quantification limit ( $L O Q)$}

The working solutions were prepared by diluting $\mathrm{Cd}, \mathrm{Cu}$ and $\mathrm{Pb}$ standard solution. Under the optimal ICP-MS conditions, the six-point calibration curves of the three metals, established by the relationships between their corresponding spectral line intensities and the concentrations, were obtained. The method blank, as an important indicator of analytical experiment, mainly involved two parts. One was the system blank, caused by the filters, CFUF membranes, piping, glassware and plasticware during the extraction operation as well as the instrument used. The other was the reagent blank, which was caused by the reagents used in the experiment such as DIW, re-distilled $\mathrm{HNO}_{3}$, $\mathrm{HCl}$, buffer, organic chelates and chloroform. In this study, the blank samples were treated repeatedly for 11 times using the developed method, and then they were determined using ICP-MS to get the blank values. The detection limits (LOD) for the target elements were assessed at 3 times of the standard deviation ( $\sigma$ ) of the blank values, and the quantification limits (LOQ) were calculated based on $10 \sigma$. The performance of the developed method is shown in Table 1.

Lower LOD and LOQ were significant guarantees for the accuracy of the experimental results (Luan et al., 2017). The linear ranges of the three metals were $0.2-444.8 \mathrm{nmol} \mathrm{L}^{-1} \mathrm{Cd}, 1.6-786.8 \mathrm{nmol} \mathrm{L}^{-1} \mathrm{Cu}$ and $0.5-241.3 \mathrm{nmol} \mathrm{L}^{-1} \mathrm{~Pb}$, respectively. As for LOD, $\mathrm{Cd}$ and $\mathrm{Cu}$ were 0.68 and $1.18 \mathrm{pmol} \mathrm{L}^{-1}$, respectively; the value of $\mathrm{Pb}$ was relatively low, approaching $0.13 \mathrm{pmol} \mathrm{L}^{-1}$; for $\mathrm{LOQ}$, all three metals were below $3.92 \mathrm{pmol} \mathrm{L}^{-1}$. In summary, LOD and LOQ of the developed method can meet the requirements of daily experiments.

\subsubsection{Extraction rate}

In order to test the extraction efficiency of the method, certain concentrations of $\mathrm{Cd}, \mathrm{Cu}$ and $\mathrm{Pb}$ standard solutions were added to the acid digested seawater collected from site Y1, then it was subjected repeatedly for 11 times to liquid-liquid extraction at the optimum conditions selected in Sections 3.1-3.5, and after that it was determined by ICP-MS. The results showed that the measured values of $\mathrm{Cd}, \mathrm{Cu}$ and $\mathrm{Pb}$ in the sample were quite consistent with the theoretical values, and the extraction rate was $92.2-100.3 \%$ (Fig. 3a).

For $\mathrm{Cd}$ and $\mathrm{Pb}$, during the entire experimental process, the adsorption of the vessels, the residues in the extraction and back

Table 1

Performance of the developed method.

\begin{tabular}{llll}
\hline & $\mathrm{Cd}$ & $\mathrm{Cu}$ & $\mathrm{Pb}$ \\
\hline Linear ranges $\left(\mathrm{nmol} \mathrm{L}^{-1}\right)$ & $0.2-444.8$ & $1.6-786.8$ & $0.5-241.3$ \\
Detection limit $\left(\mathrm{pmol} \mathrm{L}^{-1}\right)$ & 0.68 & 1.18 & 0.13 \\
Quantification limit $\left(\mathrm{pmol} \mathrm{L}^{-1}\right)$ & 2.25 & 3.92 & 0.42 \\
Enrichment factor of liquid-liquid extraction & 40 & 40 & 40 \\
\hline
\end{tabular}

extraction operations, etc., will cause metal loss and reduce the extraction efficiency. Therefore, it is necessary to select an extraction system and containers with a low adsorption effect (Cobelo-García et al., 2007). For $\mathrm{Cu}$, the extraction rate was slightly $>100 \%$. Therefore, the experimental process must be ensured by using high purity reagents, applying clean operation technique and reducing system errors. Overall, the results showed that the method used in this study had satisfactory extraction efficiency and could reach the requirement of enrichment of trace metals in seawater.

\subsubsection{Recoveries of CFUFs}

Good mass balance is a key factor for ensuring the performance of the entire CFUF system, as that described in Liu and Lead (2006) and Liu et al. (2007). In this research, mass balance was performed by the adding of known amounts of $\mathrm{Cd}, \mathrm{Cu}$ and $\mathrm{Pb}$ standard solutions into the $0.22 \mu \mathrm{m}$ filtered seawater samples from site Y1. After being successively processed by CFUFs with 10, 3 and $1 \mathrm{kDa}$ molecular weight cutoffs and the other necessary pre-processing, the concentrations of the three metals were obtained by 3 parallel determinations of ICP-MS under the optimal determination conditions. The mass balance recoveries of the three metals were calculated based on a reported formula expressed as the following form (Liu et al., 2013):

Recovery $=100 \%\left(C_{p} V_{p}+C_{r} V_{r}\right) / C_{i} V_{i}$

in which, $C_{p}, C_{r}$ and $C_{i}$ represent permeate, retentate and initial concentrations, and $V_{p}, V_{r}$ and $V_{i}$, represent permeate, retentate and initial volumes. If a recovery value is $>100 \%$, it means that the researched component is contaminated during CFUF processing; if a recovery value is $<100 \%$, there is a loss of the researched component in the CFUF process (Chen et al., 2000).

As shown in Fig. 3b-d, the results showed that the recoveries of the methods at the three different spike levels were between $83.1 \%$ and $103.5 \%$, indicating that the developed method can be applied in the separation and determination of the three colloidal metals in real seawater samples. At the same time, it should be noted that a thorough cleaning process is necessary and indispensable for improving the efficiency of the entire CFUF system and the accuracy of the experiment (Guo and Santschi, 2007).

\subsubsection{Method application for actual seawater samples}

To evaluate the applicability, the proposed method was used in the analysis of the studied trace metals in the surface seawater of two sites, namely site Y1 and Y2 in Fig. S1. Using the colloidal separation method described in Section 2.3, the colloidal matter in seawater with $1-3 \mathrm{kDa}$, $3-10 \mathrm{kDa}$, and $10 \mathrm{kDa}-0.22 \mu \mathrm{m}$ molecular weights were gained. The fraction that can pass through the $1 \mathrm{kDa}$ CFUF membrane was defined as the truly dissolved phase. After ultrafiltration, the $\mathrm{pH}$ of the samples was adjusted to 1.8 by concentrated $\mathrm{HNO}_{3}$. Then, the trace metals were enriched by the enrichment method described in Section 2.5. Finally, the samples were determined for target metals by ICP-MS.

The results showed that there was an obvious difference in both concentrations and percentages of the dissolved metals in each CFUF cutoff range at sites $\mathrm{Y} 1$ and $\mathrm{Y} 2$. In terms of concentrations, as shown in Fig. 4a, Cd, Cu and Pb at site Y1 were $0.061,2.03$ and $1.52 \mathrm{nmol} \mathrm{L}^{-1}$ in the $1-3 \mathrm{kDa}$ fraction, $0.024,1.02$ and $1.23 \mathrm{nmol} \mathrm{L}^{-1}$ in the $3-10 \mathrm{kDa}$ fraction, and $0.012,2.30$ and $1.35 \mathrm{nmol} \mathrm{L}^{-1}$ in the $10 \mathrm{kDa}-0.22 \mu \mathrm{m}$ fraction, respectively; at site Y2, their corresponding values were $0.0087,2.32$ and $1.91 \mathrm{nmol} \mathrm{L}^{-1}$ in the $1-3 \mathrm{kDa}$ fraction, $0.017,1.83$ and $3.17 \mathrm{nmol} \mathrm{L}^{-1}$ in the $3-10 \mathrm{kDa}$ fraction, and $0.012,1.04$ and $3.12 \mathrm{nmol} \mathrm{L}^{-1}$ in the $10 \mathrm{kDa}-0.22 \mu \mathrm{m}$ fraction. This obvious difference between the two sites could be attributed to spatial/temporal variations and the result of many complex biogeochemical interactions. Meanwhile, the addition of large amounts of feed and drugs during aquaculture can easily cause the accumulation of heavy metals in water bodies and sediments (Mendiguchía et al., 2006), which may be a main reason for the high $\mathrm{Pb}$ level at site $\mathrm{Y} 2$. 

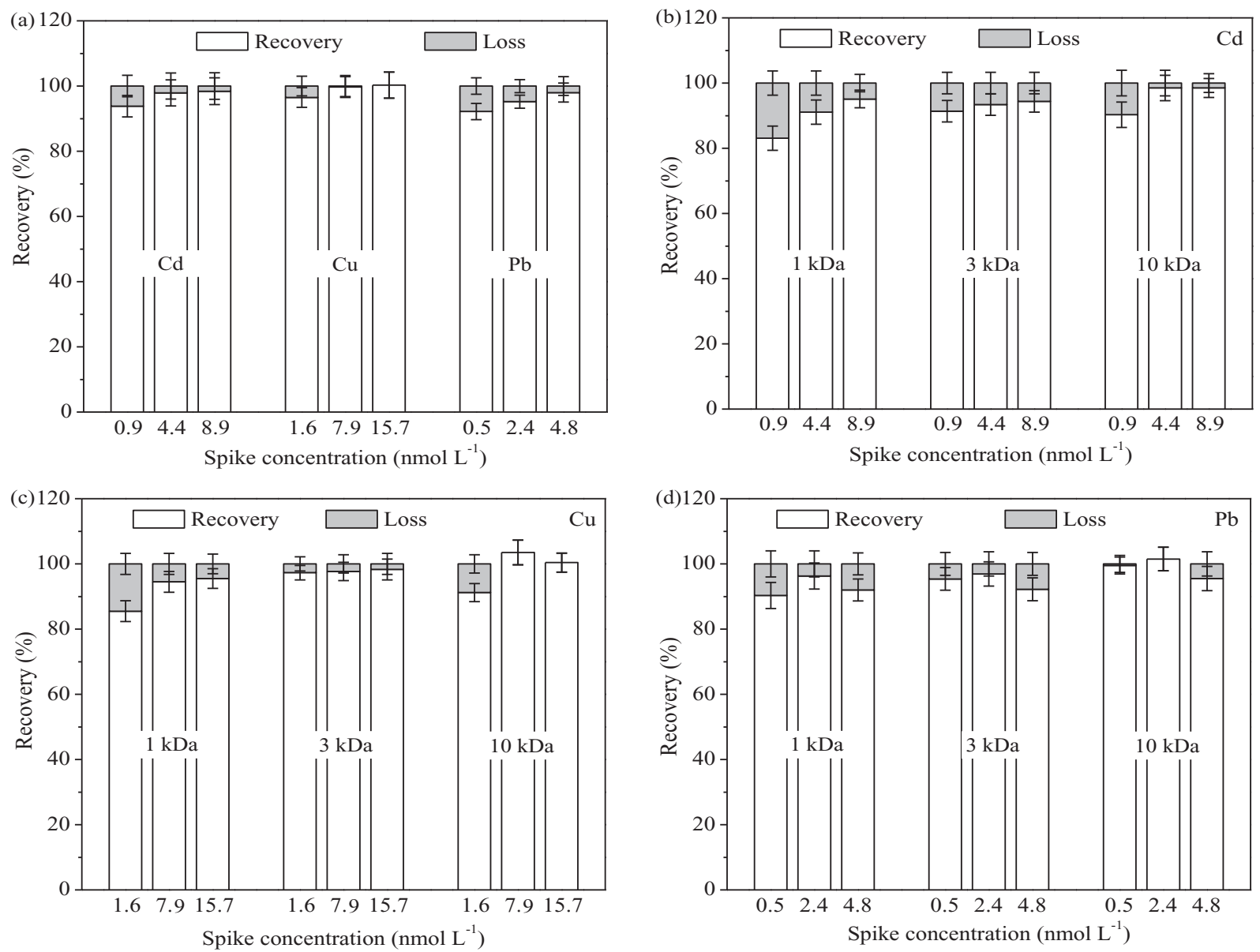

Fig. 3. Recoveries of $\mathrm{Cd}, \mathrm{Cu}$ and $\mathrm{Pb}$ in different spike concentrations (a) and in different nominal pore size of $\mathrm{CFUF}$ systems (b, $\mathrm{c}$ and $\mathrm{d}$ ).

However, the percentage distribution of the three metals among the colloidal phases $(1 \mathrm{kDa}-0.22 \mu \mathrm{m})$ and the truly dissolved phase $(<1 \mathrm{kDa})$ still had some regularity. As it can be seen from Fig. $4 \mathrm{~b}$, colloidal $\mathrm{Cd}$ and $\mathrm{Pb}$ at site $\mathrm{Y} 1$ and colloidal $\mathrm{Cd}$ and $\mathrm{Cu}$ at site $\mathrm{Y} 2$ had similar values in percentage terms, which accounted for $47-51 \%$ of the total dissolved pool; colloidal $\mathrm{Cu}$ at site $\mathrm{Y} 1$ and colloidal $\mathrm{Pb}$ at site $\mathrm{Y} 2$ also had similar values in percentage terms, which accounted for $31 \%$ of the total dissolved pool. At site $\mathrm{Y} 1$, the $1-3 \mathrm{kDa}$ fraction of $\mathrm{Cd}, \mathrm{Cu}$ and $\mathrm{Pb}$ accounted for $30 \%, 12 \%$ and $19 \%$ of their respective total dissolved concentrations, the $3-10 \mathrm{kDa}$ fraction of $\mathrm{Cd}, \mathrm{Cu}$ and $\mathrm{Pb}$ accounted for
$12 \%, 6 \%$ and $15 \%$ of their respective total dissolved concentrations, and the $10 \mathrm{kDa}-0.22 \mu \mathrm{m}$ fraction of $\mathrm{Cd}, \mathrm{Cu}$ and $\mathrm{Pb}$ accounted for $6 \%$, $13 \%$ and $16 \%$ of their respective total dissolved concentrations; at site $\mathrm{Y} 2$, the corresponding values of colloidal $\mathrm{Cd}, \mathrm{Cu}$ and $\mathrm{Pb}$ were $12 \%, 23 \%$ and $7 \%$ in the $1-3 \mathrm{kDa}$ fraction, $23 \%, 18 \%$ and $12 \%$ in the $3-10 \mathrm{kDa}$ fraction, and $15 \%, 10 \%$ and $12 \%$ in the $10 \mathrm{kDa}-0.22 \mu \mathrm{m}$ fraction. Therefore, for the colloidal fractions, these three metals were more likely to bind to the dissolved organic matter with 1-10 kDa molecular weight, indicating that the colloidal matter of this molecular weight range may play an important role in their biogeochemical cycles, which
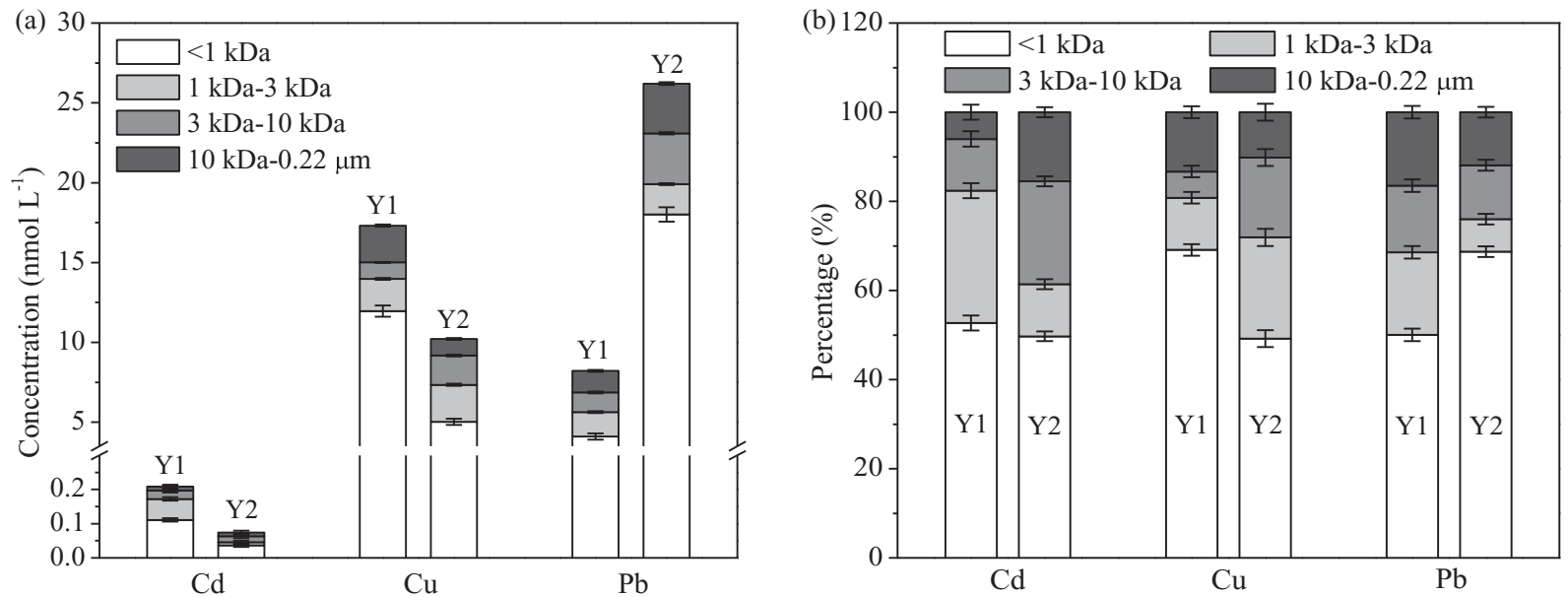

Fig. 4. Concentration and percentage distribution of $\mathrm{Cd}, \mathrm{Cu}$ and $\mathrm{Pb}$ in the dissolved fractions of samples collected in the North Yellow Sea. 


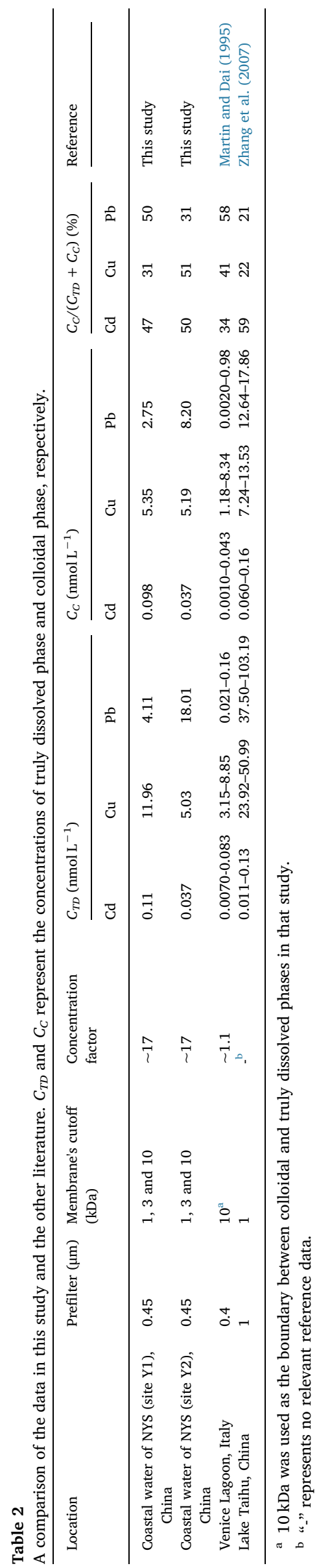

is similar to the previous report by Wen et al. (1999). Typically, organic matter with 1-10 kDa molecular weight range are primarily considered to be humic/fulvic compounds or newly released peptides such as polypeptides (Lead and Wilkinson, 2006; Kawakami et al., 2006). In addition, the degradation of particulate organic matter or the particle desorption may significantly affect the migration of the metals (Gobeil et al., 1987; Gerringa et al., 1996). Obviously, the sources of organic matter are rich and its supply is abundant in the coastal and aquaculture areas, especially estuaries.

As shown in Table 2, in comparison to other aquatic environments, the colloidal $\mathrm{Cd}$ in percentage terms in the coastal waters of the Shandong Peninsula was close to that of the Lake Taihu (59\%), but higher than that of the Venice Lagoon (34\%); the proportion of colloidal $\mathrm{Pb}$ to its value in the total dissolved pool was lower than that of the Venice Lagoon (58\%) (Martin and Dai, 1995), but higher than that of the Lake Taihu (21\%) (Zhang et al., 2007). In terms of concentration, colloidal Cd in this study was 0.037 and $0.098 \mathrm{nmol} \mathrm{L}^{-1}$, and colloidal Cu was 5.19 and $5.35 \mathrm{nmol} \mathrm{L}^{-1}$, both lower than that of the Lake Taihu, but higher than that of the Venice Lagoon; colloidal $\mathrm{Pb}$ was 2.75 and $8.20 \mathrm{nmol} \mathrm{L}^{-1}$, which was close to that of the Lake Taihu (12.64-17.86 $\left.\mathrm{nmol} \mathrm{L}^{-1}\right)$, but still higher than that of the Venice Lagoon $\left(0.0019-0.97 \mathrm{nmol} \mathrm{L}^{-1}\right)$.

Overall, the concentration of colloidal trace metals varied widely, and this phenomenon may be due to the specific properties of metals and the nature of different aquatic systems (Ingri et al., 2004). Furthermore, colloidal metals still occupy a large proportion of their total dissolved pool, which is a significant part of studying the trace metal geochemical cycle and its environmental significance (Ran et al., 2000; Singhal et al., 2006; Pourret et al., 2007). However, for a single element, it can be found that the total dissolved concentration may not play a critical role in regulating the interaction of the truly dissolved phase and each colloidal fraction. In other words, a high total dissolved concentration does not necessarily lead to an increase in the concentration of colloidal phase or each colloidal fraction, e.g. 1-3 kDa, $3-10 \mathrm{kDa}$ and $10 \mathrm{kDa}-0.22 \mu \mathrm{m}$, and the main factors affecting the migration of various metal elements remain to be further studied. Meanwhile, due to the lack of data on the spatiotemporal distribution and variation of colloidal trace metals in the NYS, there is no comparison and discussion of their monthly, seasonal or annual changes in this study.

\section{Conclusions}

A rapid, effective and sensitive method has been developed for the separation and determination of three colloidal trace metals including $\mathrm{Cd}, \mathrm{Cu}$ and $\mathrm{Pb}$ in seawater. The method provided lower detection limit and good accuracy. Excellent recoveries were successfully obtained, which was about $83.1 \%-103.5 \%$. Meanwhile, the use of the developed method allowed the effect of salt matrix to be effectively removed. The method achieved a high enrichment factor of 40, which made the separation and determination of colloidal metals in seawater more efficient.

After using this method for the analysis of the coastal waters of the Shandong Peninsula, it could be found that $\mathrm{Cd}, \mathrm{Cu}$ and $\mathrm{Pb}$ in the colloidal phase accounted for $31-51 \%$ of the total dissolved pool. In addition, the 1-10 kDa may be the key fraction of the migration process for $\mathrm{Cd}, \mathrm{Cu}$ and $\mathrm{Pb}$ in coastal ecosystem, and the main factor affecting the migration of trace metals among the fractions with different molecular weight range, e.g. $<1 \mathrm{kDa}, 1-3 \mathrm{kDa}, 3-10 \mathrm{kDa}$ and $10 \mathrm{kDa}-$ $0.22 \mu \mathrm{m}$, may not be simply the change of their total dissolved concentration.

\section{Acknowledgement}

We gratefully thank the four anonymous reviewers for their constructive comments and suggestions. This study was financially 
supported by the National Natural Science Foundation of China (41376083) and the Strategic Priority Research Program of the Chinese Academy of Sciences (XDA23050303). We thank Dr. Kai Liu for his indepth discussion and helpful advice.

\section{Appendix A. Supplementary data}

Supplementary data to this article can be found online at https:// doi.org/10.1016/j.marchem.2019.103685.

\section{References}

Achterberg, E.P., Braungardt, C.B., Sandford, R.C., Worsfold, P.J., 2001. UV digestion of seawater samples prior to the determination of copper using flow injection with chemiluminescence detection. Anal. Chim. Acta 440, 27-36.

AlSuhaimi, A.O., AlRadaddi, S.M., Al-Sheikh Ali, A.K., Shraim, A.M., AlRadaddi, T.S., 2017. Silica-based chelating resin bearing dual 8-Hydroxyquinoline moieties and its applications for solid phase extraction of trace metals from seawater prior to their analysis by ICP-MS. Arab. J. Chem. https://doi.org/10.1016/j.arabjc.2017.10.006.

Amon, R.M.W., Benner, R., 1996. Bacterial utilization of different size classes of dissolved organic matter. Limnol. Oceanogr. 41 (1), 41-45.

Auffan, M., Rose, J., Bottero, J.Y., Lowry, G.V., Jolivet, J.P., Wiesner, M.R., 2009. Towards a definition of inorganic nanoparticles from an environmental, health and safety perspective. Nat. Nanotechnol. 4 (10), 634-641.

Biparva, P., Matin, A.A., 2012. Microextraction techniques as a sample preparation step for metal analysis. In: Farrukh, M.A. (Ed.), Atomic Absorption Spectroscopy. IntechOpen Ltd, Rijeka, pp. 61-88.

Bruland, K.W., Franks, R.P., Knauer, G.A., Martin, J.H., 1979. Sampling and analytical methods for the determination of copper, cadmium, zinc, and nickel at the nanogram per liter level in sea water. Anal. Chim. Acta 105, 233-245.

Buesseler, K.O., Bauer, J.E., Chen, R.F., Eglinton, T.I., Gustafsson, O., Landing, W., Mopper, K., Moran, S.B., Santschi, P.H., VernonClark, R., Wells, M.L., 1996. An intercomparison of cross-flow filtration techniques used for sampling marine colloids: overview and organic carbon results. Mar. Chem. 55, 1-31.

Buffle, J., 2006. The key role of environmental colloids nanoparticles for the sustainability life. Environ. Chem. 3, 155-158.

Chen, M., Guo, L.D., Huang, Y.P., Gao, Z.Y., Cai, Y.H., Cai, M.G., 2000. Application of the cross-flow ultrafiltration technique to the study of colloidal uranium, thorium, radium isotopes and organic carbon in seawater. Acta Oceanol. Sin. 22 (5), 51-59.

Cobelo-García, A., 2013. Kinetic effects on the interactions of Rh(III) with humic acids as determined using size-exclusion chromatography (SEC). Environ. Sci. Pollut. R. 20, 2330-2339.

Cobelo-García, A., Turner, A., Millward, G.E., Couceiro, F., 2007. Behaviour of palladium (II), platinum(IV), and rhodium(III) in artificial and natural waters: influence of reactor surface and geochemistry on metal recovery. Anal. Chim. Acta 585 (2), 202-210.

Colombo, C., Oates, C.J., Monhemius, A.J., Plant, J.A., 2008. Complexation of platinum, palladium and rhodium with inorganic ligands in the environment. Geochem.-Explor. Env. A. 8, 91-101.

Costa, M.C., Assunção, A., Almeida, R., Costa, A.M.R., Nogueira, C., Paiva, A.P., 2018. $\mathrm{N}, \mathrm{N}^{\prime}$-dimethyl- $\mathrm{N}, \mathrm{N}^{\prime}$-dicyclohexylsuccinamide: a novel molecule for the separation and recovery of Pd(II) by liquid-liquid extraction. Ser. Purif. Technol. 201, 96-105.

Fu, J.L., Yang, Y., Peng, H., Zhou, L.M., Hou, L.J., Liu, M., 2011. Study on nanoparticles in Yangtze Estuary. Environ. Sci. 32 (7), 1924-1931 (in Chinese with English abstract).

Gerringa, L.J.A., Poortvliet, T.C.W., Hummel, H., 1996. Comparison of chemical speciation of copper in the Oosterschelde and Westerschelde Estuaries, The Netherlands. Estuar. Coast. Shelf S. 42, 629-643.

Gobeil, C., Silverberg, N., Sundby, B., Cossa, D., 1987. Cadmium diagenesis in Laurentian Trough sediments. Geochim. Cosmochim. Ac. 51, 589-596.

Gu, L.J., Yang, Y., Liu, M., Nie, M.H., Li, T., Hou, L.J., 2013. Distribution and physicochemical properties of aquatic colloids in the Yangtze Estuarine and coastal ecosystem. Environ. Sci. 34 (11), 4195-4203 (in Chinese with English abstract).

Guo, L.D., Santschi, P.H., 1997. Isotopic and elemental characterization of colloidal organic matter from the Chesapeake Bay and Galveston Bay. Mar. Chem. 59 (1-2) $1-15$.

Guo, L.D., Santschi, P.H., 2007. Ultrafiltration and its applications to sampling and characterisation of aquatic colloids. In: Wilkinson, K., Lead, J. (Eds.), Environmental Colloids and Particles: Behaviour, Separation and Characterisation. John Wiley \& Sons Ltd, Chichester, pp. 159-221.

Guo, L., Warnken, K.W., Santschi, P.H., 2007. Retention behavior of dissolved uranium during ultrafiltration: implications for colloidal U in surface waters. Mar. Chem. 107, $156-166$.

Gustafsson, O., Gschwend, P.M., 1997. Aquatic colloids: concepts, definitions, and current challenges. Limnol. Oceanogr. 42, 519-528.

Hochella, M.F., Lower, S.K., Maurice, P.A., Penn, R.L., Sahai, N., Sparks, D.L., Twining, B.S., 2008. Nanominerals, mineral nanoparticles, and earth systems. Science 319, 1631-1635.

Huang, L.L., Pu, X.M., Pan, J.F., Wang, B., 2013. Heavy metal pollution status in surface sediments of Swan Lake lagoon and Rongcheng Bay in the northern Yellow Sea. Chemosphere 93, 1957-1964.

Huang, W., Duan, D.D., Zhang, Y.L., Cheng, H., Ran, Y., 2014. Heavy metals in particulate and colloidal matter from atmospheric deposition of urban Guangzhou, South China.
Mar. Pollut. Bull. 85 (2), 720-726.

Huang, W., Zhang, Y.L., Li, H.Y., Ran, Y., 2015. Distribution and sources of heavy metals in colloidal and particulate matter in Dongjiang River basin. Acta Scien. Circum. 35 (1), 101-107 (in Chinese with English abstract).

Ingri, J., Nordling, S., Larsson, J., Rönnegård, J., Nilsson, N., Rodushkin, I., Dahlqvist, R., Andersson, P., Gustafsson, Ö., 2004. Size distribution of colloidal trace metals and organic carbon during a coastal bloom in the Baltic Sea. Mar. Chem. 91, 117-130.

Kawakami, S.K., Gledhill, M., Achterberg, E.P., 2006. Production of phytochelatins and glutathione by marine phytoplankton in response to metal stress. J. Phycol. 42, 975-989.

Kilduff, J., Weber, W.J., 1992. Transport and separation of organic macromolecules in ultrafiltration processes. Environ. Sci. Technol. 26, 569-577.

Lead, J.R., Wilkinson, K.J., 2006. Natural aquatic colloids: current knowledge and future trends. Environ. Chem. 3, 159-171.

Li, L., Liu, J.H., Wang, X.J., Shi, X.F., 2015. Dissolved trace metal distributions and cu speciation in the southern Bohai Sea, China. Mar. Chem. 172, 34-45.

Liu, R., Lead, J.R., 2006. Partial validation of cross flow ultrafiltration by atomic force microscopy. Anal. Chem. 78, 8105-8112.

Liu, R.X., Lead, J.R., Baker, A., 2007. Fluorescence characterization of cross flow ultrafiltration derived freshwater colloidal and dissolved organic matter. Chemosphere 68, 1304-1311.

Liu, R.X., Lead, J.R., Zhang, H., 2013. Combining cross flow ultrafiltration and diffusion gradients in thin-films approaches to determine trace metal speciation in freshwaters. Geochim. Cosmochim. Ac. 109, 14-26.

Liu, K., Gao, X.L., Li, L., Chen, C.T.A., Xing, Q.G., 2018. Determination of ultra-trace Pt, $\mathrm{Pd}$ and $\mathrm{Rh}$ in seawater using an offline pre-concentration method and inductively coupled plasma mass spectrometry. Chemosphere 212, 429-437.

Logan, B.E., Jiang, Q., 1990. Molecular size distributions of dissolved organic matter. J. Environ. Eng. 116 (6), 1046-1062.

Luan, F., Lu, Y.X., Li, R.C., Tang, L.L., Liu, H.T., 2017. Determination of $\mathrm{Cd}^{2+}, \mathrm{Cr}^{3+}, \mathrm{Cu}^{2+}$ and $\mathrm{Zn}^{2+}$ in traditional Chinese medicine Shuanghuanglian oral liquid by high performance capillary electrophoresis. Curr. Anal. Chem. 13, 250-255.

Manju, B.G., Swaminathan, S., Uma, M.K., John, B.B.R., 2015. A review on detection of heavy metal ions in water-an electrochemical approach. Sensor. Actuat. B-Chem. 213, 515-533.

Markus, A.A., Krystek, P., Tromp, P.C., Parsons, J.R., Roex, E.W.M., de Voogt, P., Laane, R.W.P.M., 2018. Determination of metal-based nanoparticles in the river Dommel in the Netherlands via ultrafiltration, HR-ICP-MS and SEM. Sci. Total Environ. 631-632, 485-495.

Martin, J.M., Dai, M.H., 1995. Significance of colloids in the biogeochemical cycling of organic carbon and trace metals in the Venice Lagoon (Italy). Limnol. Oceanogr. 40 (1), 119-131.

Mendiguchía, C., Moreno, C., Mánuel-Vez, M.P., García-Vargas, M., 2006. Preliminary investigation on the enrichment of heavy metals in marine sediments originated from intensive aquaculture effluents. Aquaculture 254, 317-325.

Pinto, J.J., Martín, M., Hercesesa, B., Lópezlópez, J.A., Moreno, C., 2015. Solvent bar micro-extraction: improving hollow fiber liquid phase micro-extraction applicability in the determination of $\mathrm{Ni}$ in seawater samples. Talanta 142, 84-89.

Pokrovsky, O.S., Shirokova, L.S., Zabelina, S.A., Vorobieva, T.Y., Moreva, O.Y., Klimov, S.I., Chupakov, A.V., Shorina, N.V., Kokryatskaya, N.M., Audry, S., Viers, J., Zoutien, C., Freydier, R., 2012. Size fractionation of trace elements in a seasonally stratified boreal lake: control of organic matter and iron colloids. Aquat. Geochem. 18, $115-139$.

Pourret, O., Dia, A., Davranche, M., Gruau, G., Hénin, O., Angée, M., 2007. Organocolloidal control on major- and trace-element partitioning in shallow groundwaters: confronting ultrafiltration and modeling. Appl. Geochem. 22 (8), 1568-1582.

Powell, R.T., Landing, W.M., BauerPinto, J.E., 1996. Colloidal trace metals, organic carbon and nitrogen in a southeastern U.S. estuary. Mar. Chem. 55, 165-176.

Ran, Y., Fu, J.M., Sheng, G.Y., Beckett, R., Hart, B.T., 2000. Fractionation and composition of colloidal and suspended particulate materials in rivers. Chemosphere 41 (1), 33-43.

Santschi, P.H., 2018. Marine colloids, agents of the self-cleansing capacity of aquatic systems: historical perspective and new discoveries. Mar. Chem. 207, 124-135.

Singhal, R.K., Preetha, J., Karpe, R., 2006. The use of ultrafiltration in trace metal speciation studies in sea water. Environ. Int. 32, 224-228.

Sorouraddin, S.M., Farajzadeh, M.A., Okhravi, T., 2017. Cyclohexylamine as extraction solvent and chelating agent in extraction and preconcentration of some heavy metals in aqueous samples based on heat-induced homogeneous liquid-liquid extraction. Talanta 175, 359-365.

Srichandan, S., Panigrahy, R.C., Baliarsingh, S.K., Rao, B.S., Pati, P., Sahu, B.K., Sahu, K.C., 2016. Distribution of trace metals in surface seawater and zooplankton of the Bay of Bengal, off Rushikulya estuary, East Coast of India. Mar. Pollut. Bull. 111, $468-475$.

Su, Y.D., Li, J., Huang, Y., Chen, L.W., 2006. Application of internal standardization to rapid coprecipitation technique using APDC-Cu(II) for FAAS determination of lead in salt. Spectrosc. Spect. Anal. 26 (3), 564-566 (in Chinese with English abstract).

Turner, A., Pedroso, S.S., Brown, M.T., 2008. Influence of salinity and humic substances on the uptake of trace metals by the marine macroalga, Ulva lactuca: experimental observations and modelling using WHAM. Mar. Chem. 110, 176-184.

Um, W., Papelis, C., 2002. Geochemical effects on colloid-facilitated metal transport through zeolitized tuffs from the Nevada Test Station. Environ. Geol. 43 (1/2), 209-218.

Waeles, M., Tanguy, V., Lespes, G., Riso, R.D., 2008. Behaviour of colloidal trace metals $(\mathrm{Cu}, \mathrm{Pb}$ and $\mathrm{Cd})$ in estuarine waters: an approach using frontal ultrafiltration (UF) and stripping chronopotentiometric methods (SCP). Estuar. Coast. Shelf S. 80, $538-544$. 
Wang, Z.H., Wang, X.N., 2014. Determination of cadmium, copper, lead, zinc, chromium and nickel in seawater by atomic absorption spectrometry after extraction separation. Metal. Anal. 34 (2), 44-47 (in Chinese with English abstract).

Wen, L.S., Stordal, M.C., Tang, D.G., Gill, G.A., Santschi, P.H., 1996. An ultraclean crossflow ultrafiltration technique for the study of trace metal phase speciation in seawater. Mar. Chem. 55, 129-152.

Wen, L.S., Santschi, P.H., Gill, G., Paternostro, C., 1999. Estuarine trace metal distributions in Galveston Bay: importance of colloidal forms in the speciation of the dissolved phase. Mar. Chem. 63, 185-212.

Xu, H.C., Xu, M.W., Li, Y.N., Liu, X., Guo, L.D., Jiang, H.L., 2018. Characterization, origin and aggregation behavior of colloids in eutrophic shallow lake. Water Res. 142, $176-186$.

Yang, Y.L., Yin, X.C., Mu, X.Y., Li, C.Y., Li, Y., 2001. Environmental geochemistry of Swan Lake Inlet, Rongcheng Bay, the Yellow Sea of China. Chin. J. Geochem. 20, 152-160. Zhang, Z.P., Sun, X.J., Chi, Q.Q., Zhu, G.W., Qin, B.Q., 2007. Concentrations of colloidal trace metals in Lake Taihu in spring. Environ. Chem. 26 (2), 232-235 (in Chinese with English abstract).

Zhang, Y., Gao, X.L., Wang, C.Y., Chen, C.T.A., Zhou, F.X., Yang, Y.W., 2016.

Geochemistry of phosphorus in sediment cores from Sishili Bay, China. Mar. Pollut. Bull. 113 (1-2), 552-558. 